Article

\title{
Perception of safety climate among Indonesian nurses: A cross-sectional survey
}

\author{
Evi Harwiati Ningrum, ${ }^{1}$ Sue Evans, ${ }^{2}$ Sze-Ee Soh, ${ }^{2}$ Arul Ernest ${ }^{2}$ \\ ${ }^{1}$ School of Nursing, Faculty of Medicine, Universitas Brawijaya, Malang, Indonesia; ${ }^{2}$ Monash University, \\ Melbourne, Australia
}

\begin{abstract}
Background: The measurement of nurse perception on safety, and the factors associated to safety climate, direct the development of effective strategies in reducing adverse events, and patient safety improvement.

Design and Method: This research was quantified, using the teamwork and safety climate domains of an Indonesian translated version of the Safety Attitudes Questionnaire (SAQ-INA). The teamwork and safety climate domain scores were calculated, using the published SAQ-INA scoring algorithm. The univariate and multivariate median regression models were performed to examine the association between potential predictors and safety climate.

Result: The results showed that 279 nurses responded to the survey ( $82 \%$ response rate). While most of them had a positive attitude towards teamwork $(n=170,61 \%)$, fewer possessed the same mentality towards safety climate $(n=109,39 \%)$. The lowest level of teamwork was perceived by nurses working in the emergency department (median 71, interquartile range 12.5), and safety climate (median 64, interquartile range 14.2). Furthermore, those that worked in the private hospitals, also reported lower levels of safety climate, compared to nurses in the public health centres (median difference=-3.571, $\mathrm{p}=0.009$ ).

Conclusion: Ward and hospital type were associated with the level of safety climate, perceived by nurses. Understanding the key areas, the intervention is best directed to target hospital wards with poor safety climate, in a bid to reduce adverse events, and improve patient safety.
\end{abstract}

\section{Introduction}

Patient safety is an emerging aspect of research in Indonesia, as the country progressively implements Jaminan Kesehatan Nasional (JKN), or National Universal Health coverage ${ }^{1}$, which requires accreditation from all the empanels in the public and private hospitals. ${ }^{2}$ Part of the accreditation standards, require hospi- tals to demonstrate adequate safety assurance systems. ${ }^{3}$ While the safety documentation, compiling adverse events reporting activities, hospital acquired infection control, safety policies, and drug management procedures, were observed to be completed in most hospitals accreditation surveys conducted in $2015 .{ }^{4}$ Moreover, the patient safety culture within Indonesia healthcare organisation was rarely assessed. In five of nine hospitals assessed in Australian -Indonesian study shows there were no significant impact of accreditation on organisational culture. ${ }^{4}$ Therefore, it is not assumed that accredited hospitals, also have good organisational cultures, in relation to patient safety.

Safety culture comprises of, how an individual views, perceptions, and actions to safety management system demonstrated in an organisation. 5,6 However, safety climate that represent the empirical characteristics of practice are often measured because culture is rather complex to be assessed quantitatively. ${ }^{7}$ Safety climate represents safety culture at one given point in time, and provides information about its implementation in health organisations. ${ }^{8}$ Furthermore, there are evidences from comparing most hospitals, as regards the high levels of safety climate, while those with low ranks of safety climate shows declining of healthcare outcomes including, longer length of stay, ${ }^{9}$ higher 30 -readmission rates, ${ }^{10}$ and increased postoperative mortality rate. ${ }^{11}$ With inpatient adverse event rates, estimated at $33 \%$ of admission in Indonesian hospitals, ${ }^{12}$ it is hypothesised that, improving safety climate reduces detrimental issues, improve patient well-being, hospital care and financial stability in Indonesia.

The Safety Attitudes Questionnaire (SAQ), ${ }^{13}$ is presently the most widely used safety climate tool, with evidences that support its validity, and reliability. ${ }^{13}$ Recently, the SAQ was translated into Bahasa Indonesian (SAQ-INA), with the measurement properties being examined, using Rasch analysis. ${ }^{14}$ Findings showed that the teamwork and safety climate domains of the SAQ-INA, had adequate internal construct validity, and is appropriately used to estimate the perception of safety in Indonesian hospitals. ${ }^{14}$ Therefore, this study describes the perception of safety among nurses working in Indonesian hospitals, and examine the association between demographic, professional, and organisational factors, using the domains of the SAQ-INA tool.

Significance for public health

There had been numerous studies, that showed poor safety climate and safety culture, perceived by health workers in medical services, which were associated with low hospital and protection measures such as, longer length of stay, higher 30 days readmission rates, and increased adverse events. Despite the importance, the investigation of safety climate is rarely reported by healthcare institution in Indonesia. The investigation of therapist perception towards safety climate, are essential data for Indonesian hospitals, as the nurse is the dominant workforce in the health system. 


\section{Design and Methods}

Respondents of this cross-sectional study were Indonesian licensed nurses, delivering direct clinical care to patients in the emergency department (ED), with inpatient units, at a public and private hospital in East Java, Indonesia. Both hospitals have capacities of approximately 120 to 170 beds, and employed about 250 to 300 nurses, respectively. The respondents were made eligible for inclusion in this study, when they had performed over 7.5 working hours within a week, had been nurse on duty in respective ward for two-month period prior to the survey being administered. ${ }^{15}$ This criterion was applied to ensure that, those undertaking the survey had sufficient exposure to the safety climate within the organisation. Furthermore, ethical approval was provided by the Human Research Ethic Committee, at Monash University (MUHREC 2016-1409).

Data collection was overseen by the principal investigator $(\mathrm{EN})$, that visited sites on a regular basis, to provide in-service education, and recruit respondents. The two research assistants, trained in confidentiality and privacy principles, distributed, collected, and kept the tally of surveys shared and returned, on a response rate tracker sheet, with the listed names of eligible nurses at each site, provided to the EN. After distributing an explanatory statement, and the SAQ-INA survey tool to eligible nurses, names appearing on the list were crossed off. After completion of the task, respondents were advised to place the completed survey in an envelope, and have it returned to a sealed box, located in each ward. However, consents were inferred, whenever the survey was completed.

\section{Measurement of safety climate dan factors associated with safety climate}

Based on results from the validation study, the teamwork and safety climate domains of the SAQ-INA were used in this research, to quantify the level of safety climate. Teamwork climate is personnels' perception toward quality of collaboration, while safety climate is the perception of a strong, and proactive organisational commitment to safety system. The teamwork and safety climate domains of the SAQ-INA consists of six and seven items respectively, which were measured, using a five point Likert scale, that ranged from 1 (strongly disagree), to 5 (strongly agree). Furthermore, higher scores indicated that more positive attitudes existed, towards the particular safety domain assessed.

Additional questions regarding demographic (age, gender), professional (experience level, time length working in current unit, tenure, qualification), and organisational (employment status, ward type and class, number of shifts per week, work pattern) background of respondents, were also included in the survey. Ward type was classified into six categories namely, the emergency department (ED), medical, surgical, mixed surgical-medical, Intensive

Table 1. Characteristics of nurses that responded to the SAQ-INA (Safety Attitudes Questionnaire Indonesian version) questionnaire.

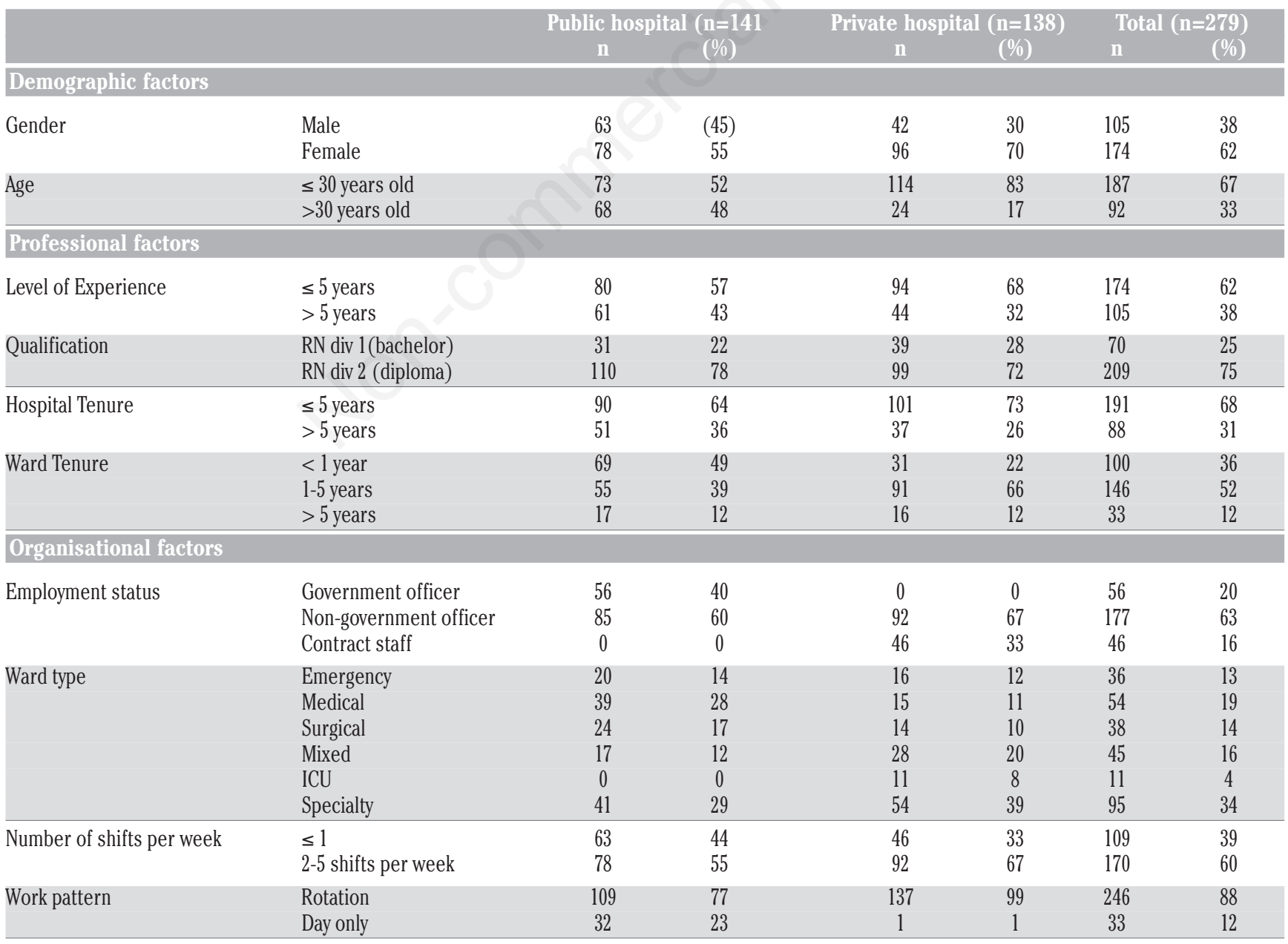

RN, registered nurse; ICU, intensive care unit. 
Care Unit (ICU), and specialty wards (paediatric, stroke, and cardiovascular). Ward class categories of lower, upper, and no class were also created for classification, based on the payment arrangements made by patients in each ward. Lower class wards included patients that were fully covered by the Indonesian Health Coverage (UHC), while those of the upper class provided services for patients that were able to afford co-payment, or private fees. The no class category was used for patients, treated in ED, ICU, the stroke, and cardiovascular units.

\section{Statistical analysis}

Descriptive statistics were used to examine the characteristics of respondents in the two Indonesian hospitals, and the SAQ-INA teamwork and safety climate domain scores. The scores of The SAQ-INA consists of domain scores calculated in accordance with the published scoring algorithm, ${ }^{13}$ the percentage of positive scale scores ( $\geq 75$ out of 100$)$, that indicate the proportion of respondents who were more likely to choose positive response (i.e., strongly agree and agree options).
Univariate and multivariate median (quantile) regression models were used, to assess the strength of the association between demographic (gender and age), professional (level of experience, work tenure, qualification), and organisational factors (employment status, ward type design, work and shift pattern), with teamwork and safety climate. ${ }^{16}$ Furthermore, the outcomes were skewed by the use of median regression, and transformation of data did not improve the distribution. Univariate regression models were initially computed for each predictor, with the teamwork and safety climate domains of the SAQ-INA. Variables that shows medium association $(\mathrm{p}<0.2)$ after univariate analysis, were subsequently entered into a multivariate quantile regression model, using a backward stepwise method. ${ }^{16}$ During the multivariate analysis, a stepwise regression model was used, with the probability of variable inclusion and exclusion set at $\mathrm{p}=0.01$ and $\mathrm{p}=0.05$, respectively. Any factors not associated significantly with the teamwork and safety climate domain ( $\mathrm{p}>0.05$ ), was removed from the model. Furthermore, differences between median of each predictor variable, were calculated for teamwork and safety climate domain.

Table 2. Teamwork climate and safety climate scores for teamwork climate and safety climate domain scores assessed by demographic, professional and organisational factors.

\begin{tabular}{|c|c|c|c|c|c|}
\hline \multirow{2}{*}{ Overall sample } & & \multicolumn{2}{|c|}{ Teamwork climate } & \multicolumn{2}{|c|}{ Safety climate } \\
\hline & & $\begin{array}{l}\text { Median } \\
75.0\end{array}$ & $\begin{array}{l}\mathrm{IQR} \\
8.3\end{array}$ & $\begin{array}{c}\text { Median } \\
71.4\end{array}$ & $\begin{array}{l}\mathrm{IQR} \\
10.7\end{array}$ \\
\hline \multicolumn{6}{|l|}{ Demographic factors } \\
\hline Gender & $\begin{array}{l}\text { Male } \\
\text { Female }\end{array}$ & $\begin{array}{l}75.0 \\
75.0\end{array}$ & $\begin{array}{l}12.5 \\
12.5\end{array}$ & $\begin{array}{l}71.4 \\
69.6\end{array}$ & $\begin{array}{l}12.5 \\
10.7\end{array}$ \\
\hline Age group & $\begin{array}{l}\leq 30 \text { years old } \\
>30 \text { years old }\end{array}$ & $\begin{array}{l}75.0 \\
75.0\end{array}$ & $\begin{array}{l}12.5 \\
12.5\end{array}$ & $\begin{array}{l}71.4 \\
67.8\end{array}$ & $\begin{array}{l}10.7 \\
14.2\end{array}$ \\
\hline \multicolumn{6}{|l|}{ Professional factors } \\
\hline Level of experience & $\begin{array}{l}\leq 5 \text { years } \\
>5 \text { years }\end{array}$ & $\begin{array}{l}75.0 \\
75.0\end{array}$ & $\begin{array}{l}13.5 \\
10.4\end{array}$ & $\begin{array}{l}71.4 \\
67.8\end{array}$ & $\begin{array}{l}10.7 \\
14.2\end{array}$ \\
\hline Qualification & $\begin{array}{l}\text { RN div } 1 \\
\text { RN div } 2\end{array}$ & $\begin{array}{l}75.0 \\
75.0\end{array}$ & $\begin{array}{c}9.3 \\
14.5\end{array}$ & $\begin{array}{l}71.4 \\
71.4\end{array}$ & $\begin{array}{l}12.5 \\
10.7\end{array}$ \\
\hline Hospital tenure & $\begin{array}{l}\leq 5 \text { years } \\
>5 \text { years }\end{array}$ & $\begin{array}{l}75.0 \\
75.0\end{array}$ & $\begin{array}{l}12.5 \\
11.4\end{array}$ & $\begin{array}{l}71.4 \\
67.8\end{array}$ & $\begin{array}{l}10.7 \\
13.3\end{array}$ \\
\hline Ward tenure & $\begin{array}{l}<1 \text { year } \\
1-5 \text { years } \\
>5 \text { years }\end{array}$ & $\begin{array}{l}75.0 \\
75.0 \\
75.0\end{array}$ & $\begin{array}{l}12.5 \\
12.5 \\
10.4\end{array}$ & $\begin{array}{l}71.4 \\
71.4 \\
67.8 \\
\end{array}$ & $\begin{array}{l}14.2 \\
10.7 \\
12.5\end{array}$ \\
\hline \multicolumn{6}{|l|}{ Organisational factors } \\
\hline Employment status & $\begin{array}{l}\text { Government officer } \\
\text { Non-government officer } \\
\text { Contract staff }\end{array}$ & $\begin{array}{l}75.0 \\
75.0 \\
75.0\end{array}$ & $\begin{array}{c}8.3 \\
16.6 \\
13.5\end{array}$ & $\begin{array}{l}67.8 \\
71.4 \\
71.4\end{array}$ & $\begin{array}{l}10.7 \\
14.2 \\
10.7\end{array}$ \\
\hline Ward type & $\begin{array}{l}\text { Emergency } \\
\text { Medical } \\
\text { Surgical } \\
\text { Mixed } \\
\text { ICU } \\
\text { Specialty }\end{array}$ & $\begin{array}{l}70.8 \\
75.0 \\
75.0 \\
75.0 \\
75.0 \\
75.0 \\
\end{array}$ & $\begin{array}{c}12.5 \\
12.5 \\
12.5 \\
12.5 \\
8.3 \\
16.6\end{array}$ & $\begin{array}{l}64.2 \\
67.8 \\
71.4 \\
67.8 \\
78.5 \\
71.4 \\
\end{array}$ & \begin{tabular}{c|}
14.2 \\
10.7 \\
7.1 \\
12.5 \\
14.2 \\
10.7
\end{tabular} \\
\hline Ward class & $\begin{array}{l}\text { Lower } \\
\text { Upper } \\
\text { No class }\end{array}$ & $\begin{array}{l}75.0 \\
75.0 \\
75.0\end{array}$ & $\begin{array}{l}12.5 \\
12.5 \\
12.5\end{array}$ & $\begin{array}{l}71.4 \\
67.8 \\
67.8\end{array}$ & $\begin{array}{l}10.7 \\
12.5 \\
14.2\end{array}$ \\
\hline Number of shift per week & $\begin{array}{l}\leq 1 \text { shift per week } \\
2-5 \text { shifts per week }\end{array}$ & $\begin{array}{l}75.0 \\
75.0\end{array}$ & $\begin{array}{l}10.4 \\
13.5\end{array}$ & $\begin{array}{l}71.4 \\
71.4 \\
\end{array}$ & $\begin{array}{l}14.2 \\
11.6\end{array}$ \\
\hline Work pattern & $\begin{array}{l}\text { Rotation } \\
\text { Day only }\end{array}$ & $\begin{array}{l}75.0 \\
75.0\end{array}$ & $\begin{array}{l}12.5 \\
14.6\end{array}$ & $\begin{array}{l}71.4 \\
67.8\end{array}$ & $\begin{array}{l}10.7 \\
16.0\end{array}$ \\
\hline Hospital & $\begin{array}{l}\text { Public } \\
\text { Private }\end{array}$ & $\begin{array}{l}75.0 \\
75.0\end{array}$ & $\begin{array}{l}12.5 \\
12.5\end{array}$ & $\begin{array}{l}71.4 \\
67.8 \\
\end{array}$ & $\begin{array}{l}10.7 \\
14.2\end{array}$ \\
\hline
\end{tabular}

Median and interquartile range were described because there was skewness of the SAQ-INA data. 


\section{Results and Discussions}

Characteristics of respondents are fully summarised accordingly in Table 1. Out of the 340 surveys that were distributed to nurses working in 17 wards across the two hospitals, 279 of it were returned, providing an overall response rate of $82 \%$ (77\% and $87 \%$ in both public and private hospitals, respectively). Most respondents were female nurses $(n=174,62 \%)$, with ages younger than 30 years old $(n=187,67 \%)$. The majority $(n=246,88 \%)$ of respondents were rostered, to work both during the day and night, while also being shown that, they had been working for less than five years $(n=174,62 \%)$. However, most nurses $(n=209,75 \%)$, received their trainings at vocational nursing colleges (nurse division 2), with $63 \%(n=77)$, employed as permanent non-government staff, which means salaries were paid to them from the hospital budget, and not by the state administration.

\section{Nurse perception on teamwork and safety climate}

During this study, $61 \%$ of most Indonesian nurses ( $n=171)$, had positive perception toward their teamwork, while only $39 \%$ $(n=108)$, reported their positive attitude toward safety. Table 2 best describes the median teamwork and safety climate, according to demographic, professional and organisational groups. The median teamwork climate SAQ-INA score was 75.0 (IQR 8.3), which was higher, compared to that of the safety climate (median 71.4, IQR 10.7) (Figure 1).

\section{Level of teamwork and safety climate in public versus private hospitals}

The teamwork and safety climate domain scores for ward type, in both public and private hospitals The Figures 1 and 2, respectively. Regardless with type of hospital, the lowest level of teamwork climate (median 70.8; IQR 12.5), and the safety climate (median 64.2; IQR 14.2) were described by nurses working in ED.

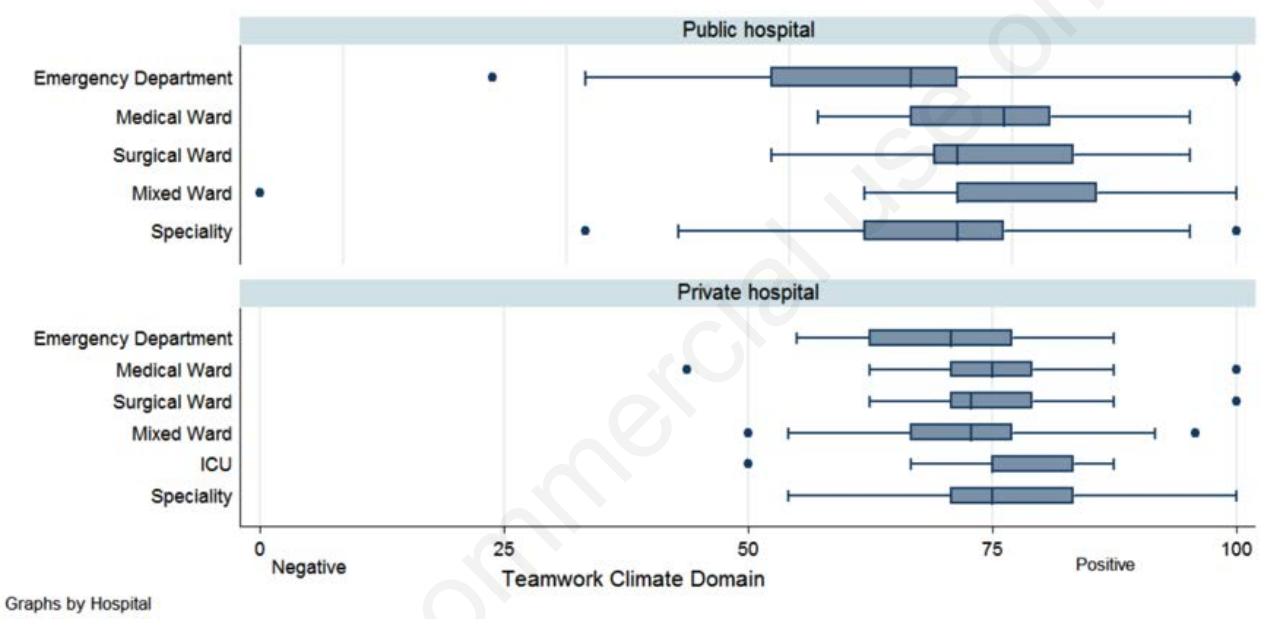

Figure 1. Boxplot of SAQ-INA teamwork climate domain scores, by hospital and ward type.

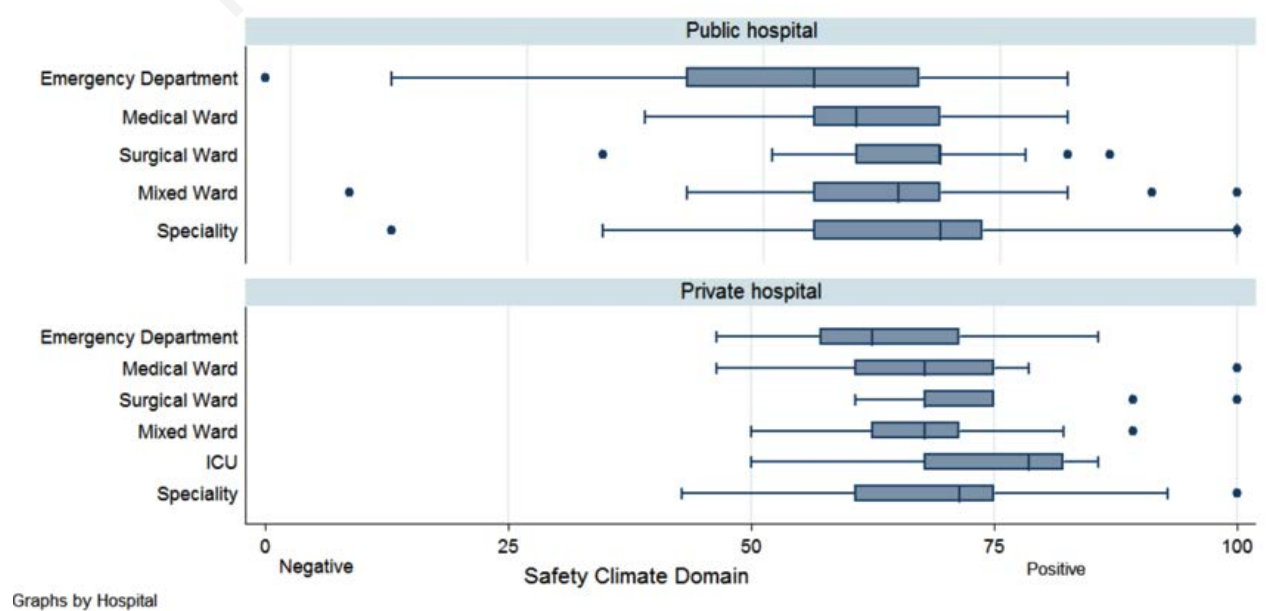

Figure 2. Boxplot of SAQ-INA safety climate domain scores, by hospital and ward type. 


\section{Factors associated with teamwork and safety climate}

The result of the univariate analysis using quantile regression for the teamwork climate and safety climate domains were presented in Table 3. Multivariate regression was performed only for the safety climate because other most factors was not significantly associated with the teamwork climate but ward type (median difference $4.2,95 \%$ CI, 0.1, 8.3), in the univariate analysis (Table 3 ). Significant predictors of high safety climate domain scores in the multivariate model included comparisons between female and male nurses, with working in all clinical areas (medical, surgical, mixed, and ICU wards) being compared to the ED. Furthermore, predictors of having low perception of safety climate included comparisons between those over 30 years and those aged $<30$, with those working in a private hospital compared to those in the public medical centres.
This is the first study measuring nurse perceptions of safety in Indonesian nurses, using a validated instrument that is Indonesian version of the SAQ (SAQ-INA) tool. While another Indonesian study had attempted to estimate safety culture, researchers used the Hospital Survey On Patient Safety Culture (HSOPSC) tool, which had not been appropriately validated in Indonesia, as results should be interpreted with caution. ${ }^{18,19}$ This study showed that, the teamwork climate domain's score was higher than that of the safety climate. Furthermore, the clinical area where nurses worked, was also observed to be the strongest determinant of teamwork and safety climate. ${ }^{20}$ This highlights the importance of explorative studies, to assess the causes of poor safety climate including, a culture of blame or unsupportive leaders in healthcare institutions, while also considering that clinical areas are where the strategies to improve climate should be focused on.

Table 3. Table univariate and multivariate quantile regression of the SAQ-INA domains score across demographic, professional and organisational factors.

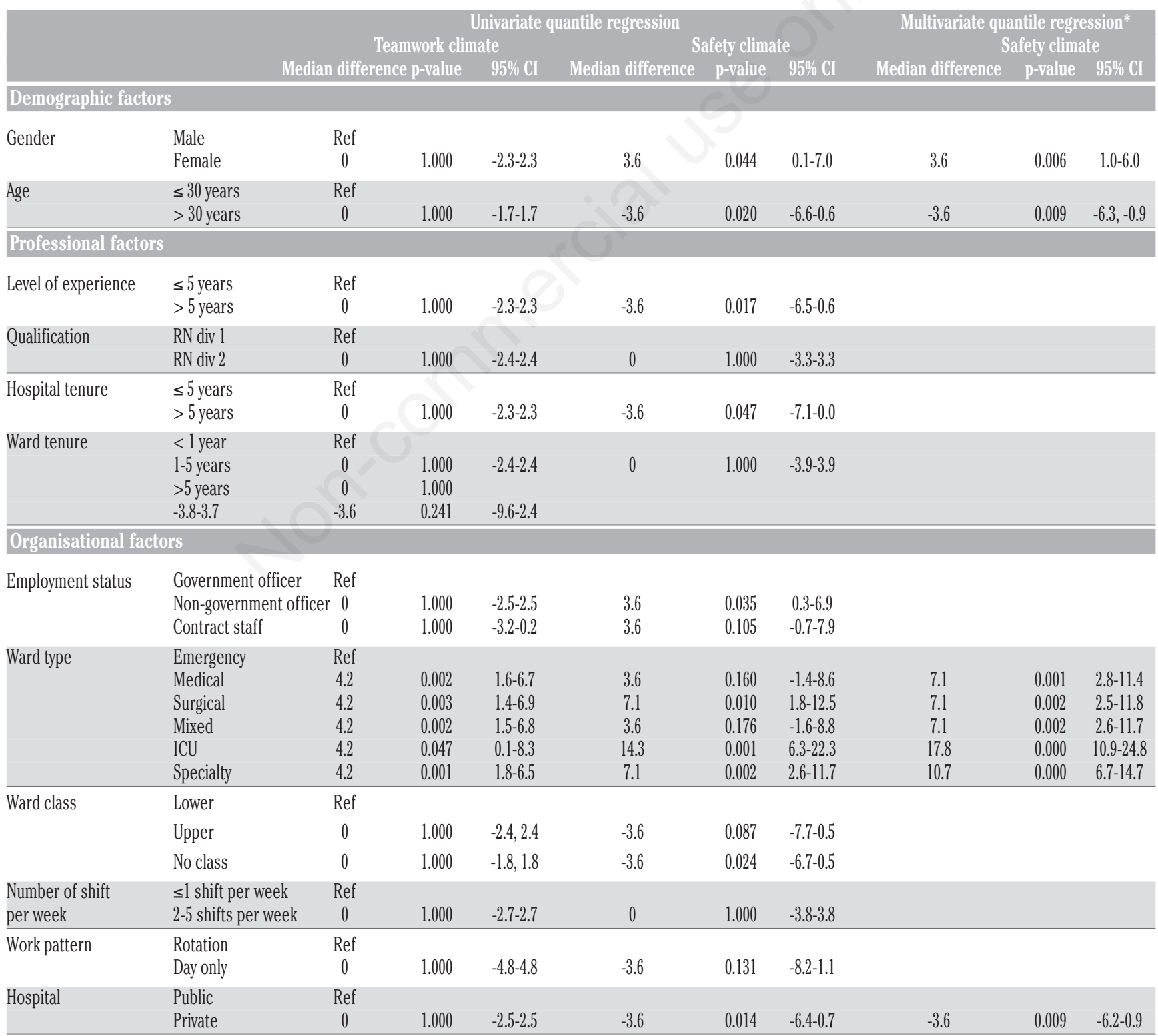

*Only associated factors that had significant p value in univariate model were inputted to multivariate model. 
Furthermore, this study observed that $61 \%$ of nurses from both participating Indonesian hospitals, had positive attitudes toward teamwork climate. This differed to a similar study conducted in six acute Australian hospitals, which observed only $51 \%$ of nurses had positive attitudes toward teamwork climate. ${ }^{21}$ This difference is probably due to the distinguished belief, values and characteristics between the two countries. ${ }^{22}$ However, only $39 \%$ of nurses had a positive attitude towards safety climate. Similar results were observed in studies undertaken in Australia, ${ }^{21}$ United States, ${ }^{23}$ Switzerland, ${ }^{23}$ Sweden ${ }^{24}$ and Malaysia, ${ }^{25}$ which showed that doctors, nurses and pharmacists scored higher in the teamwork domain, compared to the safety climate region. This further suggests that health practitioners were more likely to perceive good collaboration with team members, rather than discussing concerns around patient safety. As safety climate measures the view and perception of nurses on how a healthcare organisation demonstrate its patient safety system and policy, results coming in that, just over a third of health practitioners had a positive attitude towards safety climate is concerning, with suggestions that they probably feel unsupported and resistant to speak up, whenever safety incidents occurred in their wards.

The lowest level of teamwork and safety climate were reported by nurses who perform service in ED, compared to other wards. This is similar to the finding a large multi-site US study, which observed that ED nurse reported poorer safety climate, compared to other areas of care. ${ }^{26}$ Ineffective teamwork is often a sense of inferiority manifestation, and the hierarchical relationship between physicians and nurses, hinder the establishment of a very good teamwork. ${ }^{26,27}$ Nurses that often perceived less recognition from other professionals, tend to limit themselves from team engagement. ${ }^{26}$ The importance of having effective teamwork and safety climate in this environment is not understated. A distinguishing characteristic of working in an ED is that, nurses are managing patients often with an unclear diagnosis, ${ }^{28}$ in time critical situations, and most times, in an overcrowded environment. ${ }^{29,30}$ With a culture of poor teamwork and safety climate, all in a setting where nurses need to perform rapid assessments, while also trying to make accurate judgements, the opportunity for error to occur is pronounced. Recently, an evaluation of Indonesian national insurance observed that free medical service provided by Indonesian health system was not supported with adequate referral system between general practice and hospitals thus patients crowd in ED. ${ }^{31}$ Therefore, nurse in ED need a multifaceted intervention that include reorganize work conditions and supervising staff behaviour.

Furthermore, this study observed that nurses delivering care in the ICU, reported the highest level of safety climate. A high safety climate and positive attitudes towards safety was consistent with a study conducted in five Greek ICUs. ${ }^{32}$ The ICU nurses who have better perception toward safety climate is probably due to its wellestablished safety management and governance framework. ${ }^{33}$ As the centre of hospital quality indicator, ICUs tend to have high mortality rates, and increased chances of medication error. ${ }^{34,35}$ Therefore, complex standards and requirements such as adequate staff to patient ratios, senior nurse who own intensive care training certification and at least one specialist is on duty at all times. ${ }^{36}$ Furthermore, ICUs which occupied limited numbers of ventilator machine usually have small bed capacity in a well-structured environment. ${ }^{36,37}$ Therefore, these circumstances foster safe working environments, while contrasting those encountered by nurses working in ED.

In this study, an association was observed between the type of hospital a nurse worked in (i.e., public or private), and the safety climate domain score. While variation in safety climate across hospitals had been demonstrated in past studies, ${ }^{21,23,25}$ the association between public and private hospitals have no previous history being explored. The poorer safety climate reported in the private hospital is indirect impact of its higher financial pressures and typical private governance. ${ }^{38}$ In contrast with nurses in public hospital that paid by district or provincial government as civil servants, nurses working in private hospitals are non-government officers who receive salary from a hospital-independent budget (predominantly from a small number of sole payers). ${ }^{39}$ The cost of logistic supply for safety activities such as, hand sanitizer, a required disposable materials are not reimbursed by universal health coverage, thus it is self-funded by hospital. ${ }^{1,31,40}$ Furthermore, private hospitals in Indonesia face undeniable financial challenges, possibly leading to poor implementation of safety policy perceived by their nurses. Therefore, safety improvement initiatives in private hospitals, should be modified to be more cost effective, without compromising patient safety.

This study has some noteworthy limitations. Initially, the perception of safety reported by nurses in this small study in the two hospitals, does not represent the attitudes of other health professions. However, it is most likely that, the attitude of nurses towards teamwork and safety climate, possibly permeates to other health professionals working together with them, as known to all that nurses generally constitute the largest workforce in hospitals $(58 \%))^{41}$ Furthermore, the view of nurses in this study, does not represent that of those in other Indonesian hospitals. Attempts to minimise this impact was made, by recruiting across numerous types of clinical areas in both private and public hospitals. Nonetheless, because the population involved included only nurses from two hospitals in East Java, results does not represent Indonesian acute medical centres in general. Therefore, most Indonesian hospitals operate under the same framework of universal health coverage, which means they all possess similar safety systems, and standards of quality care. ${ }^{1}$

\section{Conclusions}

Nurses in Indonesian hospitals are found to have more positive attitudes towards teamwork, compared to safety climate. The clinical aspects of the profession were also a consistent predictor of teamwork level and safety climate perceived by Indonesian nurses. This study duly recommends that, research should now focus on investigating the factors within high performing clinical wards, in a bid to help explain good teamwork and safety climate, which in turn enables these findings to be shared more broadly. Strategies such as, TeamSTEPPS ${ }^{42,43}$ and multidisciplinary rounds, that reviews quality-safety checklists, help in improving communication, with teamwork and safety culture, provided that effective implementation, and support are made available by the institution. Therefore, results from this study provides a baseline measurement, on which the strategies are measured. 
Correspondence: Sue Evans, School of Public Health and Preventive Medicine, Monash University, Melbourne, Australia, Ph: +61 3990 30017, Email: sue.evans@monash.edu.au

Key words: Nurses; perception on safety; safety attitudes; teamwork climate; safety climate.

Acknowledgement: The authors are grateful to the Faculty of Medicine, Universitas Brawijaya, and the two hospitals involved in this study for the administrative support, during the data collection process, and also to all nurse participants for contributing their time and effort towards the success of the survey.

Contribution: All authors actively contributed to the technical help, writing assistance, and statistical analysis. They all agreed on the name arrangements, and gave full support to publish this article.

Conflict of interests: The authors confirm that, there was no known conflicts of interest associated with this publication, and no significant financial support for this work that influenced its outcome. Permission was granted from The University of Texas, to reproduce, and translate Safety Attitudes Questionnaire Ensure into Indonesian language.

Funding: This project was fully funded by DFAT, Australian Government, through Australia Awards Scholarship.

Ethical approval: Obtained through the Human Research Ethic Committee, at Monash University (MUHREC 2016-1409). The authors had received participants' written consent and distributed prior to the commencement of the study.

Conference presentation: Part of this study was presented at the $1^{\text {st }}$ International Nursing and Health Sciences Symposium, November $13^{\text {th }}$ to $15^{\text {th }} 2020$, Brawijaya University, Malang, Indonesia.

Received for publication: 18 January 2021.

Accepted for publication: 12 March 2021.

o Copyright: the Author(s), 2021

Licensee PAGEPress, Italy

Journal of Public Health Research 2021;10:2182

doi:10.4081/jphr.2021.2182

This work is licensed under a Creative Commons Attribution NonCommercial 4.0 License (CC BY-NC 4.0).

\section{References}

1. Indonesian Ministry of Health. Ministry of Health Regulation about Health Services under Indonesia Universal Health Coverage. No. 71 Year 2013. Jakarta: Indonesian Ministry of Health; 2013.

2. Indonesian Government. Indonesian presidential regulation about JKN implementation. No. 12 year 2013. Jakarta: Indonesian Government; 2013.

3. Indonesian Ministry of Health. Minister of Health Regulation about hospital accreditation. No. 012 Year 2012. Jakarta: Indonesian Ministry of Health; 2012.

4. Broughton E, Achadi A, Latief K, et al. Indonesia hospital accreditation process impact evaluation: Midline report. Bethesda: University Research Co LLC (URC); 2015.

5. Health and Safety Commission. Organising for safety: Third report of the ACSNI (Advisory Committee on the Safety of Nuclear Installations) study group on human factors. Sudbury:

HSE Books; 1993.

6. Nieva V, Sorra J. Safety culture assessment: a tool for improving patient safety in healthcare organizations. Qual Saf Health Care 2003;12:ii17-ii23.

7. Wallace J, Hunt J, Richards C. The relationship between organisational culture, organisational climate and managerial values. Int J Public Sector Manage 1999;12:548-64.

8. Brand CA, Jolley DJ, Cameron P, et al. Advice on methodology for patient safety culture survey. NHMRC Centre of Research Excellence in Patient Safety. Department of Epidemiology and Preventive Medicine, School of Public Health and Preventive Medicine Faculty of Medicine Nursing and Health Science: Monash University; 2010.

9. Huang DT, Clermont G, Kong L, et al. Intensive care unit safety culture and outcomes: a US multicenter study. Int J Qual Health Care 2010;22:151-61.

10. Hansen LO, Williams MV, Singer SJ. Perceptions of hospital safety climate and incidence of readmission. Health Serv Res 2011;46:596-616.

11. Haynes AB, Weiser TG, Berry WR, et al. Changes in safety attitude and relationship to decreased postoperative morbidity and mortality following implementation of a checklist-based surgical safety intervention. BMJ Qual Saf 2011;20:102-7.

12. Patient Safety Committee for Indonesian Hospital. [Tingkat Kejadian Tidak Diharapkan di Rumah Sakit Indonesia (Unexpected incidence rate in Indonesian hospitals)].[in Indonesian]. Jakarta: Patient Safety Committee for Indonesian Hospital; 2010.

13. Sexton J, Helmreich B, Robert L, et al. The Safety Attitudes Questionnaire: psychometric properties, benchmarking data, and emerging research. BMC Health Serv Res 2006;6:1.

14. Ningrum E, Evans S, Soh SE. Validation of the Indonesian version of the Safety Attitudes Questionnaire: A rasch analysis. PloS One 2019;14:e0215128.

15. Barker AL, Morello RT, Ayton DR, et al. Development of an implementation plan for the 6-PACK falls prevention programme as part of a randomised controlled trial: protocol for a series of preimplementation studies. Inj Prev 2016;22:446-52.

16. Koenker R. Quantile regression for longitudinal data. J Multivar Anal 2004;91:74-89.

17. Gong Z. Estimation of sample size and power for quantile regression. Degree Dissertation. Kingston: Queens University; 2016.

18. Iriviranty A, Ayuningtyas D, Misnaniarti M. Evaluation of patient safety culture and organizational culture as a step in patient safety improvement in a hospital in Jakarta, Indonesia. J Patient Saf Qual Improv 2016;4:394-9.

19. Irwandy S, Noer Bahry Noor AFA, Andi Silviyah N, et al. Patient safety culture across hospital in South Sulawesi Province, Indonesia: Comparing between urban, sub urban and rural areas. Int J Sci Res Publ 2015;26:1.

20. Rigobello MCG, Carvalho REFLd, Cassiani SHDB, et al. The climate of patient safety: perception of nursing professionals. Acta Paul Enferm 2012;25:728-35.

21. Soh SE, Morello R, Rifat S, et al. Nurse perceptions of safety climate in Australian acute hospitals: a cross-sectional survey. Australian Health Rev 2018;42:203-9.

22. Mearns K, Yule S. The role of national culture in determining safety performance: Challenges for the global oil and gas industry. Safety Sci 2009;47:777-85.

23. Schwendimann R, Zimmermann N, Küng K, et al. Variation in safety culture dimensions within and between US and Swiss Hospital Units: an exploratory study. BMJ Qual Saf 
2013;22:32-41.

24. Nordén-Hägg A, Sexton JB, Kälvemark-Sporrong S, et al. Assessing safety culture in pharmacies: the psychometric validation of the safety attitudes questionnaire (SAQ) in a national sample of community pharmacies in Sweden. BMC Clin Pharmacol 2010;10:8.

25. Samsuri SE, Lin LP, Fahrni ML. Safety culture perceptions of pharmacists in Malaysian hospitals and health clinics: a multicentre assessment using the safety attitudes questionnaire. BMJ Open 2015;5:e008889.

26. Singer SJ, Gaba DM, Falwell A, et al. Patient safety climate in 92 US hospitals: differences by work area and discipline. Med Care 2009;47:23-31.

27. Khademian Z, Sharif F, Tabei SZ, et al. Teamwork improvement in emergency trauma departments. Iranian J Nurs Midwifery Res 2013;18:333.

28. Burström L. Patient safety in the emergency department, culture, waiting, and outcomes of efficiency and quality. Sweden: Uppsala University; 2014.

29. Vieth TL, Rhodes KV. The effect of crowding on access and quality in an academic ED. Am J Emerg Med 2006;24:787-94.

30. Cowan RM, Trzeciak S. Clinical review: emergency department overcrowding and the potential impact on the critically ill. Crit Care 2004;9:291.

31. The Economist [Internet]. Universal health coverage in Indonesia - one year on. 2015. Accessed: 2020 Nov 26. Available from: https://www.eiu.com/public/topical_report.aspx?campaignid $=\mathrm{i}$ ndonesiahealthcare

32. Raftopoulos V, Pavlakis A. Safety climate in 5 intensive care units: a nationwide hospital survey using the Greek-Cypriot version of the safety attitudes questionnaire. J Crit Care 2013;28:51-61.

33. Sahebalzamani M, Mohammady M. A study of patient safety management in the framework of clinical governance according to the nurses working in the ICU of the hospitals in the East of Tehran. Iran J Nurs Midwifery Res 2014;19:295.
34. Guidet B, González-Romá V. Climate and cultural aspects in intensive care units. Crit Care 2011;15:312.

35. Colla J, Bracken A, Kinney L, et al. Measuring patient safety climate: a review of surveys. Qual Saf Health Care 2005;14:364-6.

36. College of Intensive Care Medicine of Australia and New Zealand. Minimum Standards for Intensive Care Units Australia 2010. Accessed: 2020 Nov 20. Available from: https://www.cicm.org.au/CICM_Media/CICMSite/CICMWebsite/Resources/Professional\%20Documents/IC-1Minimum-Standards-for-Intensive-Care-Units.pdf

37. The Directorat General of Health Efforts Development (MoH). Technical guidance for the implementation of intensive care unit service. Jakarta: Ministry of Health; 1966.

38. Indonesian Hospital Association. Consultation paper. Indonesian Hospital Association role and response to ministry of health regulation no. 64/2016 to prevent hospital bankruptcy. Surabaya: Indonesian Hospital Association Press; 2016.

39. Indonesian Ministry of Health. Ministry of Health Regulation No. 12 year 2013, Rate pattern of hospital as a public entity. Jakarta: Ministry of Health; 2013.

40. Indonesian Ministry of Health. Ministry of Health Regulation No. 27 year 2014 About technical guidance for INA CBGs implementation. Jakarta: Indonesian Ministry of Health; 2014.

41. Australian Institute of Health and Welfare. AIHW national health workforce. Canberra: Australian Institute of Health and Welfare; 2014.

42. Mayer CM, Cluff L, Lin W-T, et al. Evaluating efforts to optimize TeamSTEPPS implementation in surgical and pediatric intensive care units. Jt Commn J Qual Patient Saf 2011;37:365-74.

43. Thomas L, Galla C. Building a culture of safety through team training and engagement. BMJ Qual Saf 2013;22:425-34.

44. Stein J, Payne C, Methvin A, et al. Reorganizing a hospital ward as an accountable care unit. J Hospital Med 2015;10:3640 . 